\title{
Knowledge and practices in the wake of novel corona virus (COVID-19) pandemic.
}

1. MBBS, FCPS

Assistant Professor

Baqai Medical University Karachi.

2. MBBS, FCPS

Assistant Professor

Baqai Medical University Karachi.

3. MBBS, MRCP, MRCGP,

DP (Dermatology)

Assistant Professor

Baqai Medical University.

4. $\mathrm{PhD}(\mathrm{SCM})$

NUST.

5. MBBS, FCPS

Assistant Professor

Baqai Medical University Karachi.

6. MBBS, FCPS

Associate Professor

Baqai Medical University Karachi.

Correspondence Address:

Dr. Bushra Rabbani

Baqai Medical University.

bushboom@yahoo.com

Article received on:

$16 / 09 / 2020$

Accepted for publication:

$28 / 11 / 2020$
Bushra Rabbani' ${ }^{1}$ Ammarah Saeed ${ }^{2}$, Faisal Ahmed ${ }^{3}$, Hafiz Tahir Mehmood ${ }^{4}$, Mariam Tariq ${ }^{5}$, Adil Khan ${ }^{6}$

ABSTRACT... Objective: This study aims to assess the knowledge and practices towards novel corona virus pandemic (COVID-19) among general patients of a tertiary care hospital in Gadap town, Karachi, Pakistan. Study Design: Cross Sectional study. Setting: OPD of Fatima Hospital, Baqai Medical University, Karachi. Period: $16^{\text {th }}$ to $21^{\text {st }}$ March 2020 . Material \& Methods: A total of 267 respondents were included using non-probability convenience sampling. Knowledge and Practices towards COVID-19 were assessed using interview based, open-ended questionnaire. The knowledge questionnaire consists of 11 questions assessing, General information, symptoms, modes of disease spread, methods of disease control and selfisolation techniques. Practice assessment was based on five parameters towards prevention. Mean knowledge and practice scores were calculated. A bivariate Pearson correlation, independent sample T-test and One Way ANOVA were utilized to depict statistical correlations between variables. Post-Hoc Analysis was applied within the demographic groups. Results: The mean age of participants was $37.33+15.1$ years, $64.8 \%$ were 40 \& below age, $64.4 \%$ were male, $40.4 \%$ belonged to Pushtoon, $43.3 \%$ were illiterate, $24.3 \%$ were laborer and $27 \%$ were housewives. The mean knowledge score was $9.31+5.59$ out of 30 , depicting an overall $31 \%$ rate of knowledge. The mean practice score was $1.33+1.34$ out of 5 . There is a strong positive $(p<0.001)$ correlation between knowledge and practice scores were found. The knowledge and practice scores were also significantly associated with level of education $(p<0.001)$. Conclusion: The overall knowledge and practices towards COVID-19 were found to be very poor in population of low socioeconomic status with low educational background improvising the public health authorities to design the specialized health education interventions aimed at targeting the specific population.

Key words: $\quad$ COVID-19, Knowledge, Self-Isolation, Pandemic, Practice.

Article Citation: Rabbani B, Saeed A, Ahmed F, Mehmood T, Tariq M, Khan A. Knowledge and practices in the wake of novel corona virus (COVID-19) pandemic. Professional Med J 2021; 28(6):784-798. https://doi.org/10.29309/TPMJ/2021.28.06.6083

\section{INTRODUCTION}

Novel coronavirus was first isolated in January 2020 in a cluster of 27 patients presenting with Pneumonia reported to Chinese Health Commission on $31^{\text {st }}$ December 2019, in Wuhan City, Hubei Province, China. ${ }^{1,2}$ It appears to be threatening as an outbreak of severe respiratory disease in countries around the world. On $30^{\text {th }}$ January 2020, the World Health Organization declared the outbreak as "a public health emergency of international concern" (PHEIC) ${ }^{3}$ and on $11^{\text {th }}$ March 2020, WHO publicly characterized COVID-19 as a "pandemic". ${ }^{4}$ As of $15^{\text {th }}$ March, 2020 , there have been around 153,517 reported cases of COVID-19 infection with 5,735 reported deaths all over the world. ${ }^{5}$

On February 11, 2020, the World Health Organization formally named the disease caused by novel coronavirus as coronavirus disease 2019 (COVID-19). ${ }^{6}$ Coronaviruses are a large family of viruses that can cause infection in humans causing varying degrees of illness ranging from symptoms of common cold to severe lifethreatening infections. Other coronavirus strains include Middle East Respiratory Syndrome (MERS) and Severe Acute Respiratory Syndrome (SARS) which have been responsible for causing life-threatening epidemics in the world. Since COVID-19 is genetically related to corona virus 
related to SARS outbreak in $2003^{7}$ therefore, International Committee on Taxonomy of Viruses (ICTV) named the virus as "severe acute respiratory syndrome coronavirus 2 (SARSCoV-2)" while related, the two viruses are different. ${ }^{8}$ The virus appears to have originated in bats and is suspected to have transmitted to humans through yet unknown intermediary animals that were either handled or consumed by humans. ${ }^{7,9}$ The disease is spread by humanto-human transmission via infected droplets ${ }^{10}$ or direct contact, and infection has been estimated to have median incubation period for COVID-19 of approximately 5 days, similar to SARS. ${ }^{11}$ The common symptoms of COVID-19 are fever, dry cough, headache, upper airway congestion, sore throat, sputum production, breathlessness, myalgia/arthralgia and diarrhea. ${ }^{1,12}$ The disease is mild in most people, in elderly with comorbidities, it may progress to pneumonia, acute respiratory distress syndrome (ARDS) and multi- organ dysfunction. ${ }^{13}$ Many infected people may remain asymptomatic. ${ }^{10,14}$ The reported severe/critical case ratio is approximately $7-10 \%$ and median time to intensive care admission is 9.5-10.5 days with mortality of around $1-2 \%$ varied geographically. ${ }^{15}$

As COVID-19 is a new discovery to medical science and is a rapidly spreading contagious infection amongst humans with limited availability of knowledge on its spread and lack of research on its treatment and prevention at current times, we are uncertain regarding the exact process of spread of COVID-19 from person to person. In comparison to its two predecessors, SARS-CoV and MERS-CoV, the SARS-Cov2 tends to spread faster but appears to have lower mortality. So far, the treatment for COVID-19 is supportive. ${ }^{1,16}$ No vaccine has been developed so far and no antiviral treatment is recommended for COVID-19 as yet but research on prevention and treatment is underway globally. The only reliable evidence available on prevention of spread so far is from the lockdown of 17 cities in Hubei province and the implementation of nationwide spread prevention measures which efficiently prevented an exponential growth of infectivity in a number of cases in China. ${ }^{17}$ Therefore, applying preventive measures to reduce the spread of the disease is of utmost importance. Preventive measures include social distancing, increasing personal hygiene measures specially hand hygiene, respiratory etiquette, and cleaning and disinfecting surfaces. ${ }^{12,18}$

In China, the prevention and control measures taken by the government at all levels have shown very significant effects, effectively curbing the spread of the COVID-19. ${ }^{19}$ The World Health Organization (WHO) reminds all countries and communities that the spread of this virus can be significantly slowed or even reversed through the implementation of robust containment and control activities. The preventive measures, adopted by Chinese government are positive and effective, and are unanimously accepted by the expert group at the World Health Organization.

For the first time in Pakistan, Health authorities confirmed two cases of COVID-19 on $1^{\text {st }}$ March $2020^{20}$, who were reported to have returned back to Pakistan after travelling internationally and developed initial respiratory symptoms of infection on their return. On $15^{\text {th }}$ March 2020, Pakistan Ministry of health confirmed 52 cases under federal and provincial quarantine. Among the 52 reported cases, 48 have travelled to a known epidemic area of COVID-19 while 4 cases of local transmission have been documented. No deaths have been reported till $15^{\text {th }}$ March 2020. ${ }^{21}$ Pakistan, being a developing country with low literacy rate amongst general population and limited availability of resources for screening and treating infected individuals, must make efforts to stop, contain, control, delay and reduce the impact of this virus at every opportunity. In view of the above, every person has a civic duty and responsibility to contribute towards the prevention of spread of COVID-19 infection amongst general public to protect themselves and their families at home, their local communities, their colleagues at workplace, public transport and the healthcare system.

At this time, due to the limited research available on COVID-19 treatment, current evidence suggests that every effort should be made individually and nationally to contain the virus and slow the 
spread of the infection to save lives. This study aims to determine the knowledge, and practices of general patients towards COVID-19, presenting in OPD of all specialties in a tertiary care hospital, Gadap town, Karachi. Hence we expect that the results from this study will help the concerned health authorities and other stakeholders to develop comprehensive, rapid and effective measures to ensure proper health education and practices to fight against this pandemic.

\section{MATERIAL \& METHODS}

This cross-sectional study was conducted just a week before the lockdown in Karachi, from $16^{\text {th }}$ to $21^{\text {st }}$ March 2020, at Fatima hospital, Baqai medical university, Gadap town, Sindh, after approval of synopsis by Ethics Review Committee at Baqai Medical University. (Ref: BMU-EC/2020-04(OL).

As the disease was new and the published literature was not available, so we used a precision estimate of $6 \%$ and anticipated knowledge of $50 \%$ (the most conservative value). Using a 95\% Confidence interval, 267 completed questionnaires would be sufficient to accurately assess knowledge, and practices about novel corona virus. Participants were interviewed using non-probability convenience sampling.

Study participants were the patients of both genders, aged 18 and above, presenting to the general out-patient department at Fatima hospital for any clinical problem, were enrolled in the study by non-probability convenience sampling. Four study teams were formed for data collection. Each team consisted of one supervisor (study investigator), two interviewers (male and female) and one translator. The interviewers were voluntarily nominated house officers and postgraduate trainees, working in the department of Internal Medicine, who can understand and speak regional languages fluently. The supervisors and interviewers were given adequate knowledge of COVID-19 symptoms, prevention and control measures in a tutorial prepared by the group of investigators under current WHO guidelines. ${ }^{22}$ They were also trained for study objectives and methodology to help with protocol and questionnaire adaptation and to prevent and prepare for challenges that may be encountered during interview. Participants were interviewed using a structured and standardized questionnaire after informed verbal consent and explaining the purpose of the study in language based on the preference of the respondent to ensure consistent wording. Participation was voluntary and the participants retained a right to withdraw at any stage of the study. The respondents were also given the opportunity to ask questions at any time. Each questionnaire was kept anonymous and collected data was also kept confidential. The data collection methods posed no risk to the study participants. All the questionnaires after completion, were reviewed on daily basis, by the supervisor, for completeness and accuracy, to maintain standards of quality control for data collection and documentation. Allocation of data entry was made on daily basis for data storage. All data collection was directly supervised by a principal investigator who monitored study teams at regular intervals.

The questionnaire was designed and approved by an expert group of Epidemiologist, Senior Internal Medicine Consultants and qualified Family physician using WHO guidelines ${ }^{22}$ on COVID-19 and included an in-depth interview based questionnaire having open-ended questions (options were not given to answer but whatever replied by respondents, were just marked in questionnaire) that were framed in a manner that minimized bias and best reflected knowledge and practices. The questionnaire was originally developed in English language and were filled by interviewers after interviewing the participants in their native language. The content and face validity of the questionnaire was assessed by two Internal Medicine consultants and an Epidemiologist. The questionnaire was pilot tested through small numbers of interviews $(n=15)$ to ensure clarity of questions and to avoid ambiguity. The questionnaire was then finalized after appropriate modifications done by valuable feedback of supervisors and interviewers. Questionnaire reliability coefficient obtained by calculating Cronbach's Alfa was found to be adequate $(0.74){ }^{23}$ 


\section{Questionnaire Content}

The questionnaire was based on four sections. Section a included questions on demographics of participants including age, gender, ethnicity, level of education and occupation. Section B comprised of 11 questions that were designed to elicit knowledge of the disease. Each correct answer was awarded 1 point and Zero for wrong answer and unanswered questions. The questions (K1-K5) was related to general knowledge about outbreak news, name of virus, prognosis of disease, medicine and vaccination for disease, with 1 point for each. The question (K6) was about people at risk with 3 correct answers. The knowledge of testing for disease (K7) had two correct answers. The knowledge of symptoms of disease (K8) was scored among six correct answers. The knowledge of mode of spread (K9) and methods of prevention (K10) included five correct answers for each. The knowledge of selfisolation (K11) had 4 correct answers. The total score was calculated by adding up 11 questions scores. The maximum achievable knowledge score was 30.

Section $\mathrm{C}$ had one question to elicit the source of information of the participants for the disease while section D was intended to measure participant's practices towards prevention comprising of five parameters of measurements with 1 point awarded for each practice used for prevention. The maximum attainable score was 5 .

Data entry and analysis was performed using SPSS v.21. Categorical variables were described using frequency and percentages. Continuous variables were summarized using mean \pm standard deviation. A bivariate Pearson correlation, independent sample T-test and One Way ANOVA were utilized to depict statistical correlations between variables. Post-Hoc analysis was performed to describe the statistical correlation within the groups of different demographic categories. Using confidence interval of $95 \%$, the significance level was considered significant when $P$ values were 0.05 or less.

\section{RESULTS}

A total of 267 participants were included in the study. The mean age of participants was $37.33+15.1$ years with range of minimum 18 and maximum 90 years. Male represented $64.4 \%$ (172) of the sample. The majority, $40.4 \%$ (108) belonged to Pushtoon ethnicity. By occupation, $30 \%$ (80) were general workers, $24.3 \%$ (65) were laborer and $10.1 \%$ (27) were students. Housewives represented $27 \%$ (72) of this sample. In total, 43.3\% (116) were illiterate. However, just able to read were $23.2 \%$ and graduate and above were $7.1 \%$. The key demographic characteristics used in this study are shown in Table-I.

\begin{tabular}{|l|c|}
\hline \multicolumn{1}{|c|}{ Category } & Total $(\mathbf{n = 2 6 7 )}$ \\
\hline Age & $37.33+15.1(18-90)$ \\
\hline 40 and below & $64.8 \%(173)$ \\
\hline $41-60$ & $28.5 \%(76)$ \\
\hline 60 and above & $6.7 \%(18)$ \\
\hline Gender & \\
\hline Male & $64.4 \%(172)$ \\
\hline Female & $35.6 \%(95)$ \\
\hline Ethnicity & \\
\hline Pushtoon & $40.4 \%(108)$ \\
\hline Sindhi & $23.2 \%(62)$ \\
\hline Punjabi & $6 \%(16)$ \\
\hline Urdu speaking & $7.1 \%(19)$ \\
\hline Balochi & $10.1 \%(27)$ \\
\hline Others & $13.1 \%(35)$ \\
\hline Education & \\
\hline Illiterate & $43.4 \%(116)$ \\
\hline Able to read & $23.2 \%(62)$ \\
\hline Primary - Middle & $9 \%(24)$ \\
\hline Matric- Intermediate & $17.2 \%(46)$ \\
\hline Graduate \& above & $7.1 \%(19)$ \\
\hline Occupation & \\
\hline Laborer & $24.3 \%(65)$ \\
\hline General worker & $30 \%(80)$ \\
\hline Students & $10.1 \%(27)$ \\
\hline Unemployed & $8.6 \%(23)$ \\
\hline Housewives & $27 \%(72)$ \\
\hline & \\
\hline & \\
\hline & \\
\hline & \\
\hline
\end{tabular}

Table-I. Demographic characteristics.

\section{Knowledge of Participants}

For reflection of final results, the first and 
foremost requirement was to calculate the overall knowledge score and practice prevention score of all the respondents which was done in SPSS through computation. Range of knowledge score is from 0 to 30 whereas the range of practice prevention score was computed as 0 to 5 . Among 267 participants, the mean knowledge score was $9.31+5.59$ with the minimum score of 0 and maximum score of 23 , depicting an overall $31 \%(9.31 / 30 \times 100)$ rate of knowledge about this pandemic disease. Table-II reflects the complete picture of knowledge and practice prevention scores against all demographic characteristics.

\section{Knowledge Range of Participants}

Knowledge range of participants was computed on the basis of their knowledge scores. On the overall range of 0 to 30 , following four ranges were defined for better comparisons and subsequent analyses as shown below in Table-III.

\begin{tabular}{|l|c|c|}
\hline $\begin{array}{c}\text { Knowledge Score } \\
\text { (Range) }\end{array}$ & Rating & Percentage \\
\hline Zero (0) & Zero & 3.7 \\
\hline $1-10$ & Insufficient & 54.7 \\
\hline $11-20$ & Sufficient & 39.7 \\
\hline $21-30$ & Good & 1.9 \\
\hline
\end{tabular}

Table-III. Knowledge score range vs rating.

Results compiled among demographic categories of age group, gender, ethnicity, occupation and education are summarized in Table-IV.

The table highlights the group or category with range and percentage knowledge ratings. As evident from the table above, in total, 3.7\% (10) had no knowledge, while $54.7 \%$ (146) demonstrated

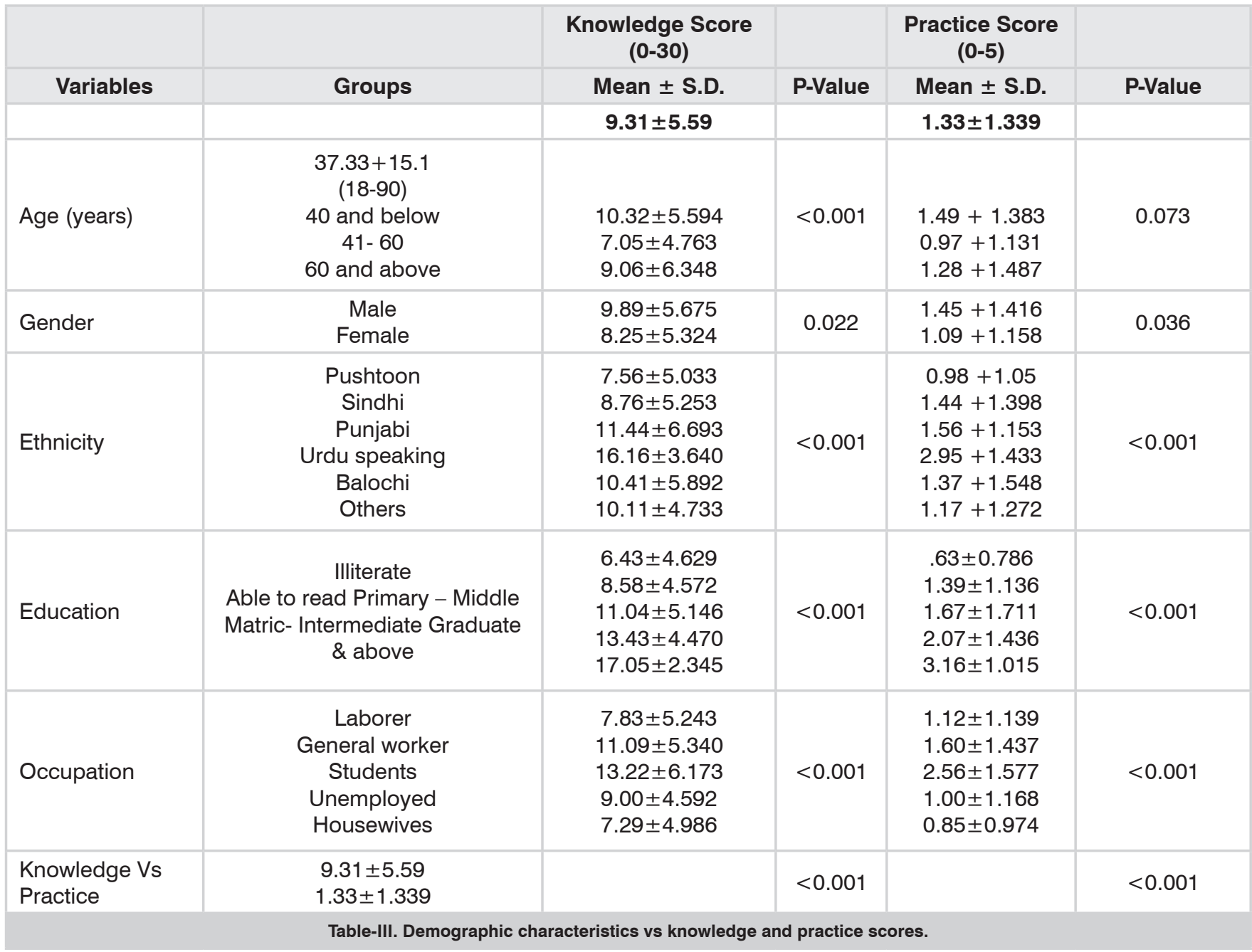


insufficient knowledge and $39.7 \%$ (106) had sufficient knowledge about pandemic. Only $1.9 \%$ (5) participants exhibited good knowledge.

Out of 10 (3.7\%) participants with zero knowledge, majority were Pushtoon 60\% (6), illiterate $80 \%$ (8), between $40-60$ years of age $70 \%$ (7), with equal gender distribution and all the females 50\% (5), were housewives.

Among 146 participants who demonstrated insufficient knowledge, majority were below 40 years 59.5\% (87), male 59.5\% (87), illiterate 59.5\%
(87) and Pushtoon 47.3\% (69) ethnicity.

Only $1.9 \%$ (5) participants exhibited good knowledge. Among them, $80 \%$ (4) were male and students of graduation and above.

\section{Knowledge Parameters towards Covid-19}

The questionnaire contained few important investigations regarding present knowledge towards COVID-19 at different parameters. Results of these investigations are presented in Table-V.

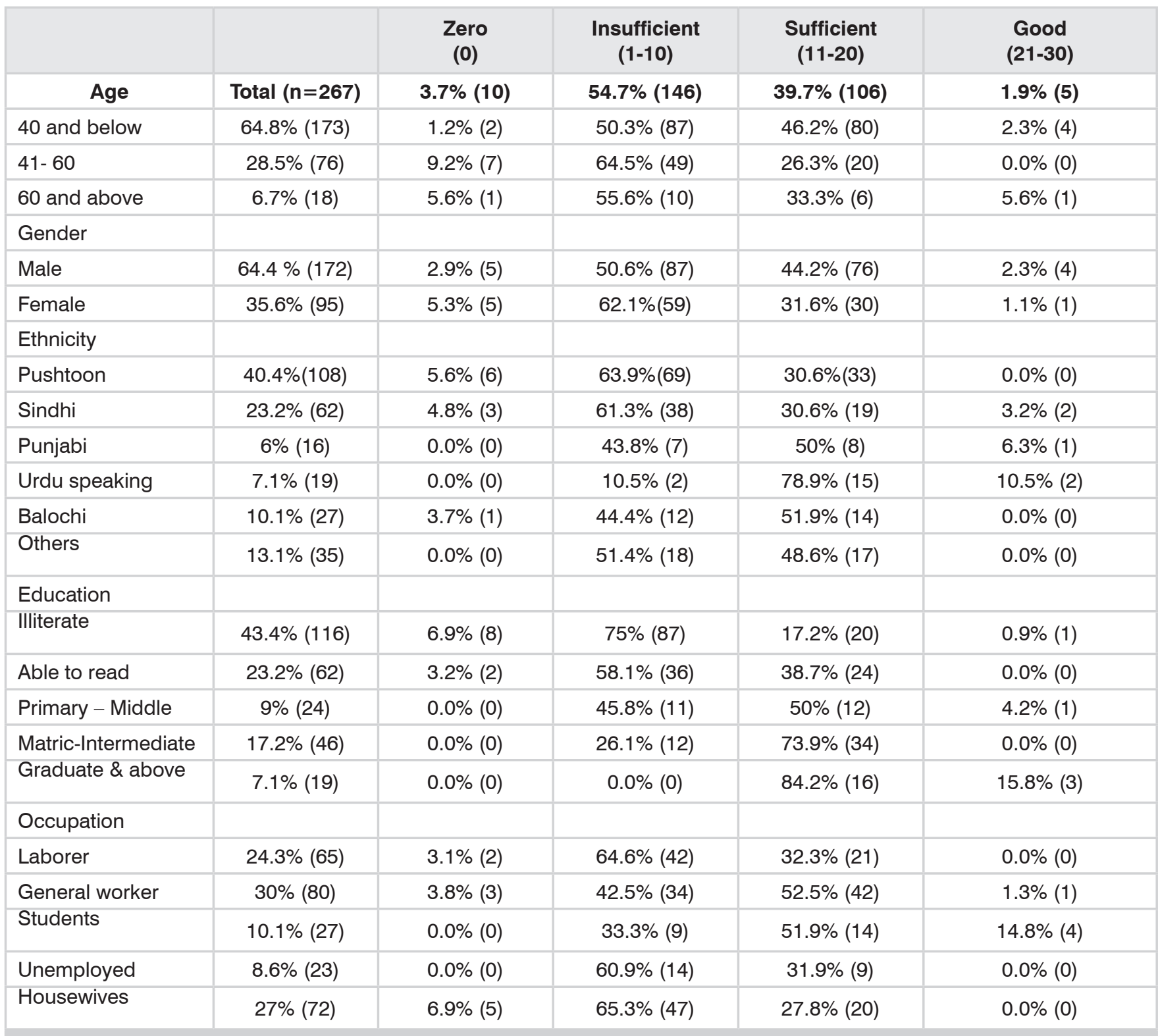

Table-IV. Demographic category wise knowledge ratings. 


\begin{tabular}{|c|c|c|}
\hline & General Parameters & Knowledge Percentage $(n=267)$ \\
\hline K1 & Info about Outbreak of disease & $95.9 \%$ \\
\hline K2 & Virus name & $77.2 \%$ \\
\hline K3 & Prognosis of disease & $16.5 \%$ \\
\hline K4 & Non availability of Medicine for COVID-19 & $54.7 \%$ \\
\hline K5 & Non availability of Vaccine for Virus & $55.1 \%$ \\
\hline K6 & Knowledge about people at risk & \\
\hline 1 & Older people & $42.3 \%$ \\
\hline 2 & People with co-morbids & $11.2 \%$ \\
\hline 3 & Pregnant & $3 \%$ \\
\hline K7 & Testing for disease & \\
\hline 1 & Flu like symptoms with $\mathrm{h} / \mathrm{o}$ travel from endemic area in last 14 days & $33.7 \%$ \\
\hline 2 & Having close contact with confirmed/suspected corona case & $12 \%$ \\
\hline K8 & Symptoms & \\
\hline 1 & Dry Cough & $53.2 \%$ \\
\hline 2 & Runny nose/sore throat & $45.7 \%$ \\
\hline 3 & Fever & $44.6 \%$ \\
\hline 4 & Shortness of breath (SOB) & $3 \%$ \\
\hline 5 & Body aches/Tiredness & $14.2 \%$ \\
\hline 6 & Diarrhea & $0.7 \%$ \\
\hline K9 & Cause of disease spread & \\
\hline 1 & Coughing/Sneezing & $41.6 \%$ \\
\hline 2 & Touching objects/surfaces & $36.3 \%$ \\
\hline 3 & Air born droplets & $34.8 \%$ \\
\hline 4 & Touching eyes, nose, and mouth & $12 \%$ \\
\hline 5 & Sharing utensils & $5.6 \%$ \\
\hline K10 & Disease spread control & \\
\hline 1 & Hand Washing & $54.3 \%$ \\
\hline 2 & Avoiding public places & $33.3 \%$ \\
\hline 3 & Covering nose and mouth by arm when coughing and sneezing & $28.1 \%$ \\
\hline 4 & Avoiding close contact with patients with flu like symptoms & $26.2 \%$ \\
\hline 5 & Avoid touching eyes, nose and mouth if hands are not clean & $12 \%$ \\
\hline K11 & Self-isolation techniques & \\
\hline 1 & Self-isolation up to 14 days & $31.8 \%$ \\
\hline 2 & Not using public transport/ taxi & $19.5 \%$ \\
\hline 3 & Not going to work, school or public place & $18.4 \%$ \\
\hline 4 & Avoiding visitors to home & $11.6 \%$ \\
\hline
\end{tabular}

Table-V. Knowledge parameters towards COVID-19.

\section{General Info about COVID-19}

The first and foremost part of the survey was the general info about the corona (COVID-19) virus disease. Though a large percentage of respondents were familiar with the outbreak of this disease $(95.9 \%)$ as well as the name of the virus $(77.2 \%)$ through different modes, however, other elements of general information show extremely poor results. More than $50 \%$ knew that there is no vaccine and medicine available for the disease.

\section{Symptoms Awareness}

Among symptoms, dry cough, runny nose/sore throat, and fever were the most known symptoms with $53.2 \%$ (142), 45.7\% (122) and 44.6\% (119) respectively. Only $3 \%$ considered SOB and less than $1 \%$ considered diarrhea as symptoms of COVID-19.

\section{Awareness to Modes of Disease Spread}

As far as the awareness and familiarization to causes of disease spread is concerned, table-V shows that $41.6 \%$ (111) had knowledge about coughing and sneezing, 36.3\% (97) knew about 
touching contaminated objects/surfaces and $34.8 \%$ (93) had correct knowledge of air-born droplets as source of spread. Only 12\% (32) knew that touching eyes, nose and mouth should be avoided if hands are not clean. Only 5.6\% (15) knew that sharing utensils can also spread the disease.

\section{Knowledge about Self-Isolation Techniques}

Results show that knowledge and awareness about self-isolation techniques were again very poor amongst the respondents. Only $31.8 \%$ (85) participants had knowledge of self-isolation for duration of 14 days and only $11.6 \%$ (31) knew that visitors should be avoided at home during self-isolation. Measures like going to work, public places or use of public transport, were also not considered to be recognized isolation methods by a large percentage of respondents.

\section{Knowledge of Disease Spread Control}

About knowledge of disease prevention, frequent hand washing is the most $54.3 \%$ (145) known preventive measures. Only $33.3 \%$ (89) had knowledge that avoiding public places can reduce the spread of this viral pandemic. Knowledge of covering nose and mouth by arm, when coughing and sneezing and avoiding close contact with patients of flu like symptoms were $28.1 \%$ (75) and $26.2 \%$ (70) respectively. This implies extremely low knowledge on disease prevention approaches by the respondents.

\section{Practice Prevention}

Practice prevention score was computed using SPSS. Practice prevention range of participants was computed on the basis of their prevention scores. On the overall range of 0 to 5, four ranges, as depicted in Table-VI below, were defined for better comparisons and subsequent analyses. The mean practice score was $1.33+1.34$. Among 267 participants, 35.6\% (95) were not practicing (practice score 0) any preventive measures at all while $43.1 \%$ (115) had insufficient practice (score1-2). Only $19.5 \%$ (52) were found to have sufficient (score 3-4) practice and merely 1.9\% (5) showed good practice with score 5.

\begin{tabular}{|l|c|c|}
\hline $\begin{array}{c}\text { Prevention Score } \\
\text { (Range) }\end{array}$ & Rating & $\begin{array}{c}\text { Practice } \\
\text { Prevention } \\
\text { Percentage }\end{array}$ \\
\hline Zero (0) & Zero & 35.6 \\
\hline $1-2$ & Insufficient & 43.1 \\
\hline $3-4$ & Sufficient & 19.5 \\
\hline 5 & Good & 1.9 \\
\hline \multicolumn{2}{|c|}{ Table-VI. Practice prevention score range vs rating. } \\
\hline
\end{tabular}

The most observed practices were frequent hand washing $49.4 \%$ (132) followed by avoidance of public places $27 \%$ (72). Use of hand sanitizers and mask were not frequent, $20.2 \%$ (54) and 20.6\% (55) respectively. Covering nose and mouth by arms when coughing and sneezing were the least frequent methods of prevention used i.e. $15.4 \%$ (41). Graphical representation of overall results of prevention practices thus achieved, is reflected in Figure-1.

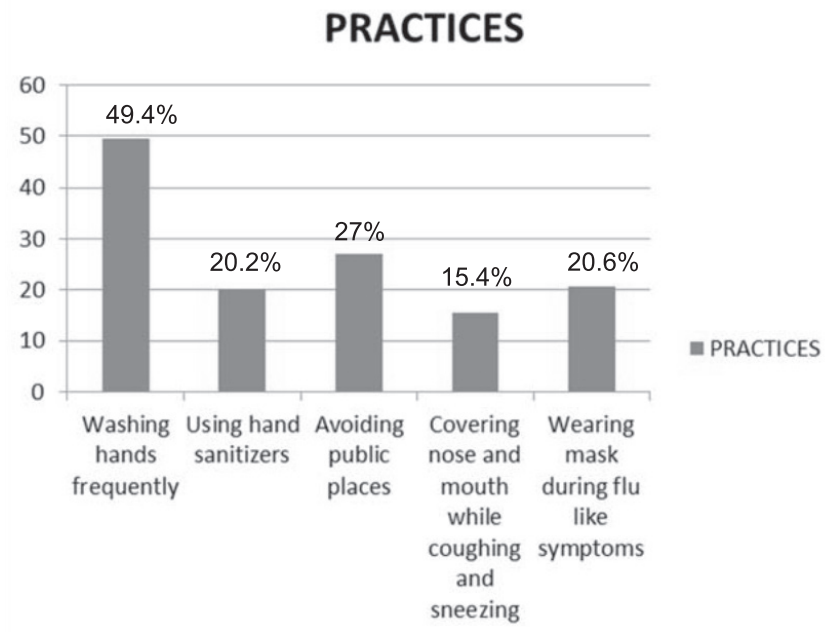

Figure-1. Percentage of prevention practices.

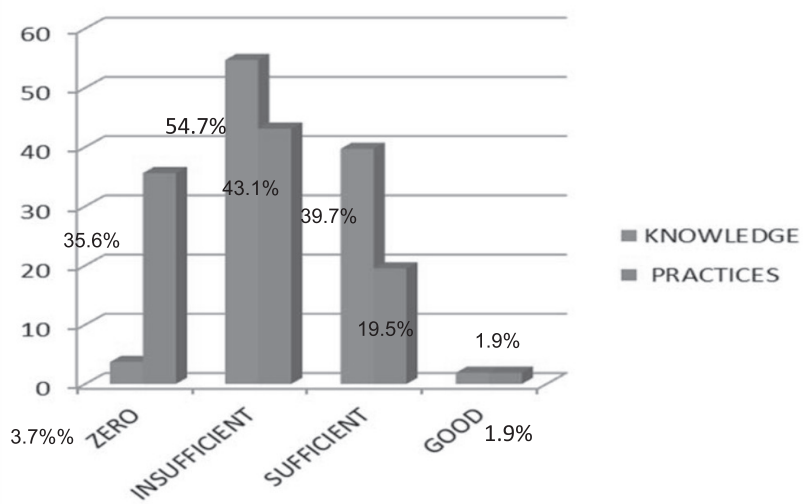

Figure-2. Comparison between knowledge and practice ranges. 


\section{Knowledge Vs Practice}

Comparison between knowledge and practice score in terms of percentages is shown below in Figure-2. The results reflected in the bar chart indicate that the two have not much difference except for a large percentage (35.6\%) with zero practices towards prevention.

\section{Statistical Correlation}

Using the bivariate correlation, strength and direction of linear relationship between different variables were analyzed using SPSS. In addition to correlation coefficient, significance was also checked using $\mathrm{p}$-value of different relationships to establish the statistical evidence. The bivariate Pearson Correlation in this case was used to measure correlations among variables like knowledge and practice scores, age vs knowledge and practice scores.

As shown in Table-II, the result implies that the knowledge of respondents has statistically significant ( $p$-value $<0.001)$ positive strong correlation $(0.5<|r|)$ with practice prevention score (0.681). The direction of the relationship between knowledge and prevention scores is positive, meaning that these variables tend to increase together (i.e., higher knowledge means higher prevention practice scores). The magnitude, or strength, of the association between knowledge score and prevention practice is strong $(0.5<|r|)$. P-Value indicates that the relationship is statistically significant at 0.01 level for 2-tailed test performed in SPSS.

The age of respondents also has negative weak correlation with knowledge score $(-0.201)$ as well as prevention score $(-0.110)$. The direction of the relationship of age with knowledge and practice score is negative, meaning that knowledge and practice score tends to increase with lower age. This also confirms our earlier findings that lower the age we have, better knowledge and practice prevention scores (negative correlation). P-Values indicate that the relationship between knowledge and age is statistically significant with $p=0.001$, while between age and practices prevention score is insignificant with $p=0.073$.
Independent samples T-test was utilized to compare means of knowledge and practice scores across categories of gender and were found to be statistically significantly different among males and females $(p=0.022 \& p=0.036$ respectively).

The mean knowledge and practices scores were also found to be significantly different across levels of education, ethnicity and occupation with $(p<0.001$ for all) using One Way ANOVA.

\section{Post-hoc analysis among demographic groups}

Post-Hoc analysis was applied among demographic groups and found some important associations as represented in Table-VII. Post-hoc analysis within the age groups depicted that age 40 and below, has significantly $(p<0.001)$ higher knowledge score (3.271) than age group between 41-60 but not having significant difference with the age group above 60 . No significant differences of practices were found within age groups.

Among group of different levels of education, the illiterate has significantly lower knowledge and practice score than others having different level of education $(p<0.001$ for all except with those who are just able to read $p=0.023$ ).

Among different ethnic groups, Pushtoon and Sindhi have significantly lower knowledge and practice scores than Urdu speaking with $p$-values $<0.001$ while Punjabi has insignificantly lower knowledge score $(p=0.080)$ than Urdu speaking but with significantly different practice score $(p=0.016)$. However, Balochi exhibited significant knowledge and practice difference than Urdu speaking with $p$ - values $=0.003 \& 0.001$.

By occupation, laborers and housewives represented having lower knowledge score than students $(p<0.001$ for both) and general workers $(p<0.002$ and $<0.001))$ while regarding practices, laborers have lower practice score compare to students $(p<0.001)$ and general workers $(p=0.152)$. The housewives showed lower practice score than students and general workers $(p<0.001$ and 0.002$)$. Housewives have lower knowledge and practice scores than laborer 


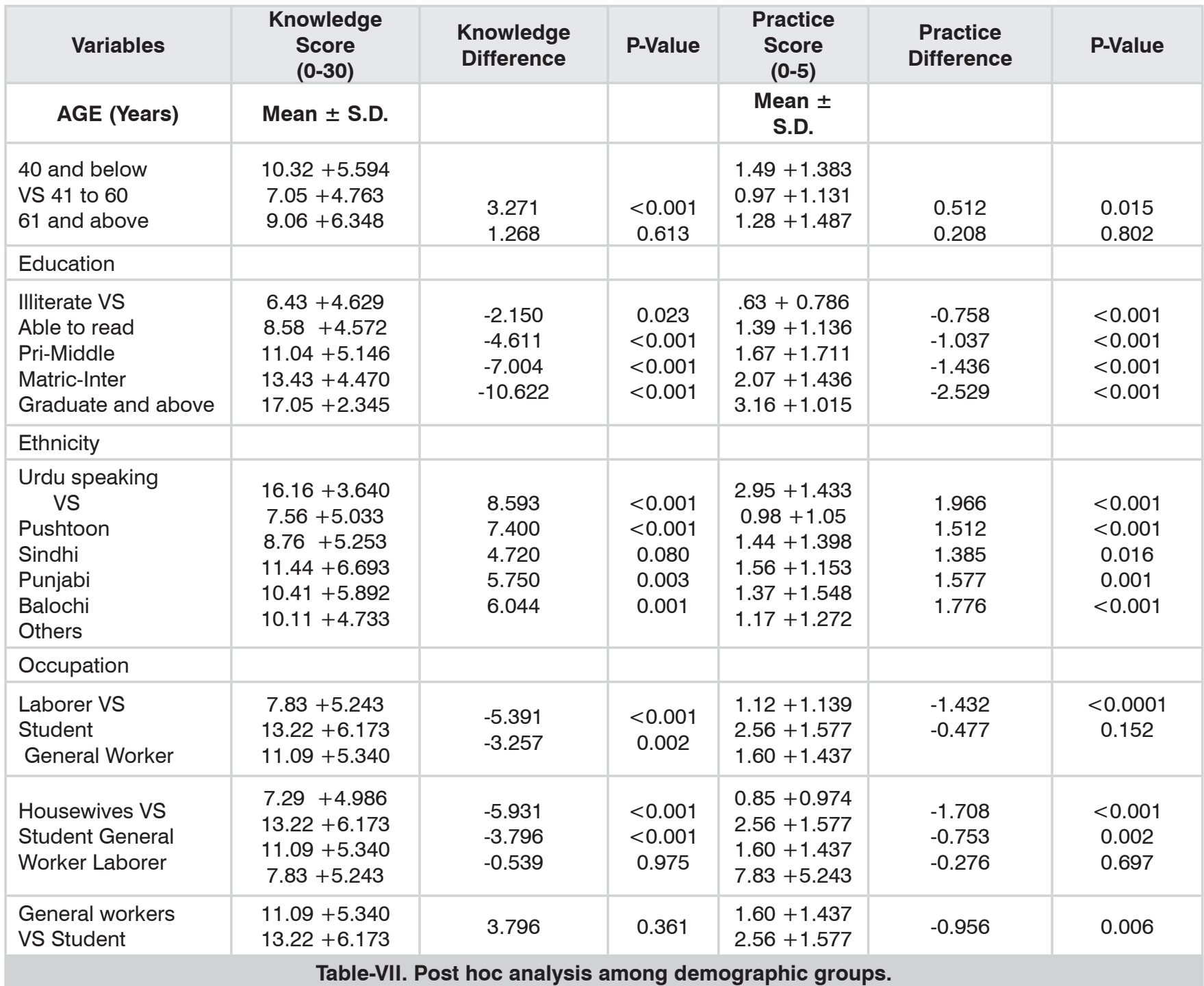

but this difference is insignificant with $\mathrm{p}$ value $=$ $0.97 \& 0.67$ respectively. The General workers have insignificantly lower knowledge score $(p$ $=0.361$ ) than students with significant practice difference $(p=0.006)$.

\section{Source of Information}

Mass media (TV) $(32.3 \%)$, social media $(28.8 \%)$ and friends/family (29.2\%) were found to be three main sources of information in this study followed by doctors/paramedics and print media comprising only $3.7 \%$ and $2.2 \%$ respectively. Remaining $3.7 \%$ showed no source of information for this pandemic with zero knowledge as shown below in Figure-3.

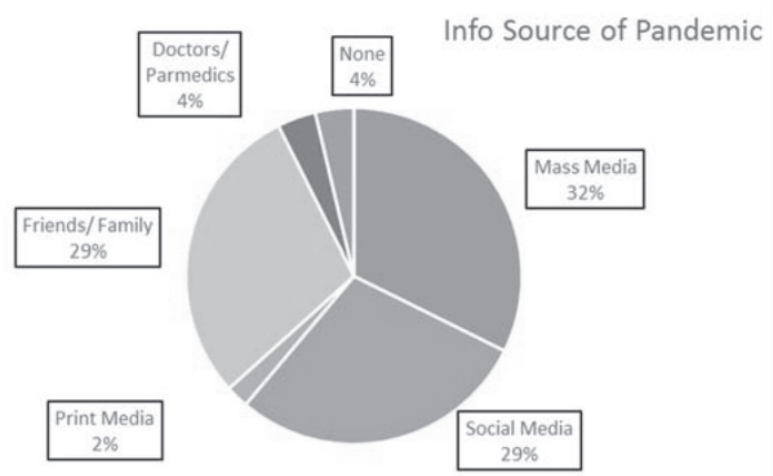

Figure-3

\section{DISCUSSION}

In this predominantly, young, male and Pushtoon population of the study group, the overall $31 \%$ 
rate of knowledge with mean knowledge score of $9.31+/-5.59$ was not surprising, because the majority of the respondents were illiterate or were only able to read (cumulative percentage of $67 \%$ ) whom knowledge and practices were assessed by an in-depth (open-ended) interview based questionnaire during the early days of COVID-19 cases reported in Pakistan, giving the mirror image of true situation.

Even in this era, where the world has become a global village, in this study $4 \%$ participants were unaware about any outbreak of novel coronavirus while $23 \%$ didn't know the name of corona virus till $15^{\text {th }}$ march 2020, after two and half month of Wuhan outbreak in China and a week before lockdown in Karachi despite the overwhelming news report of this pandemic emergency. Even though the vast majority of participants were illiterate and they also had access and understanding of the use of information resources like social media as well as mass media (TV) emphasizing the need of health education programs for COVID-19 prevention in their local languages on National television, local cable channels as well as on social media.

The assessment of "knowledge of prognosis" indicates that a very small number of participants $16.5 \%$, were aware of the fact that most of the people acquiring coronavirus infection will recover without any serious illness. ${ }^{10,14}$ This reflects that the majority of participants being unaware may contribute to unnecessary panic. ${ }^{24,25}$

Regarding knowledge about people at risk, only $42.3 \%$ knew about "older people" being vulnerable to the lethal consequences of COVID-19. ${ }^{13}$ As we are well nourished with social and cultural norms of caring our elderly at home, providing awareness to the elderly and their carers regarding older people as vulnerable population for COVID-19, might ensure prevention practices towards COVID-19 to protect their loved ones. Despite the fact that the study population was the general patients of OPD, who may be considered as more concerned towards health issues, only $11.2 \%$ knew that people with comorbidities are more at risk of serious illness from COVID-19. ${ }^{13}$
The knowledge of testing for disease appears to be correlated with the knowledge of symptoms, with only $33.7 \%$ participants were aware that one should be tested for COVID-19 if they develop flu-like symptoms specially in relation with travel history to an endemic area during last 14 days.

Approximately more than half of the participants, was aware about non-availability of any kind of medicine or vaccination for this pandemic till date ${ }^{1,16}$ but despite claiming the above, they were barely familiar with the modes of disease spread, disease prevention methods and self-isolation techniques.

The knowledge of "frequent hand washing" 54.3\% was the most known preventive measure along with being the most frequent practice as well. This may be attributed to the religious believes related to attain cleanliness by ablution "The WAZU". The poor "knowledge and practice of avoiding public places" could be due to the timings of the study being conducted before the implementation of lockdown anywhere in Pakistan. Knowledge of "covering nose and mouth by arms when coughing and sneezing" was also inadequate with least frequent practice of prevention used. "Use of hand sanitizer and mask" was also not frequent as observed among Chinese residents ${ }^{26}$ we also observed that not even all the literate, who had adequate knowledge of disease spread, were using hand sanitizers and mask probably because of low socioeconomic status.

These potentially low knowledge and prevention practices could primarily be attributed to the study been conducted in early phase of pandemic in Pakistan before lockdown in Karachi. The above findings of poor knowledge and practices are in contrast with the findings of a KAP study among Chinese residents showing higher knowledge rate and practices towards COVID-1926 but consistent with the previous KAP studies on viral hepatitis done in Pakistan. ${ }^{27,28}$ The contrary findings are primarily due to the fact that the Chinese population in the above study was well educated and had relatively high socioeconomic status as compare to the population in this study. 
The strong positive correlation found between level of education and knowledge as well as practice scores with $p$ value of $<0.001$ clearly indicates that higher the education level, higher will be the knowledge and practices. All the people having bachelor's degree or above, had highest knowledge (17.05 +/-2.345) and practice scores (3.16 +/- 1.015). Among only 5 participants, who exhibited good knowledge, 4 were students of graduation and above. The students' scores for both knowledge and practice prevention were much higher than others, obviously because of better education level, ability to read and comprehend the knowledge. The illiterate had significantly lower knowledge (6.43 +/- 4.629) and practice $(0.63+/-0.786)$ scores than others having different levels of education. Majority of the ones who were just able to read $58 \%$, as expected, demonstrated insufficient knowledge as well as poor practice score. The strong association of level of education with knowledge and practices in this study are similar with the findings of previous studies. . $^{27,28,29}$

It is very essential for the demographic data to be analyzed in the study as this will ensure that the key demographic attributes are transparent and known, as recommended by Bryman and Bell $(2015)^{30}$ as well as Saunders, Lewis and Thornhill (2012). ${ }^{31}$ This will, in the long run, ensure that some of the emerging trends can be explained from the perspective of the demographic characteristics (Leedy and Ormrod, 2013). ${ }^{32}$ Hence, the knowledge and practice prevention scores were also correlated with other demographic characteristics and revealed some important associations.

From the foregoing analysis, it can be seen that the distribution had a positive skewness, with the majority of the respondents being relatively younger and very few respondents with the age bracket of over 60 years. The results depicted that the younger the age, the better we have knowledge and practices. Among age groups, 40 years and below had highest knowledge and practice prevention score than age group between 41-60 years $(p<0.001 \& p=0.015)$ and age group above 60 years $(p=0.613 \& 0.802)$.
This is partly due to the fact that the younger age group included students and General workers, being more educated exhibited better knowledge and practices than others.

As far as the knowledge and practices across gender are concerned, male participant had significantly higher scores for knowledge and practice prevention ${ }^{29}$ as compared to female participants who were mostly housewives and majority being illiterate showed significantly lower knowledge and practice scores than students and general workers. These findings were consistent with a KAP study among mothers on newborn care done in Sindh. ${ }^{33}$ The majority of the male respondents were from general worker and laborer class with low educational background. The laborers represented having significantly lower knowledge score than students and general workers while regarding practices the laborers also had lower practice score compare to students $(p<0.001)$ and general workers $(p=0.152)$.

The study provides a glimpse of knowledge and practices towards COVID-19 amongst a group of people representing rural areas of the country living at the outskirts of a metropolitan city and is an eye opener for the Health authorities and stakeholders to be aware of the level of understanding and implementation of measures to prevent the spread of COVID-19 and saving lives. According to different surveys ${ }^{34}$ available, $17.8 \%$ population of Pakistan have access to internet (2016), 16.5\% listen to the radio (2014), access to personal TV 118/1000 (2018), literacy rate $59.13 \%$ (2017). This clearly shows that nearly half of the population of Pakistan, especially in rural areas, are likely to remain unaware of the essential knowledge and standard practices in recognizing signs of infection, taking preventive measures to prevent the spread and seeking medical help reflecting the need for taking judicious measures to spread the knowledge and teach preventive practices in all the possible languages and areas of Pakistan.

This study has some limitations. Although the study showed strong association between 
participant's knowledge and their practices, but this association could be further investigated by assessing the attitudes of participants which were not addressed in this study due to limited time and resources. Having an open ended questionnaire in the study, the knowledge and practices might have been underestimated due to recall bias and overestimated due to group of population studied who were the general patients of OPD and might be considered to be more concerned about their health issues compare to general population. Hence, there is a need for similar studies done on a larger scale in general population and addressing the factors we were unable to capture, such as "Attitude towards COVID-19" in order to generalize the findings on general population.

\section{CONCLUSION}

In developing countries like Pakistan, the longterm lockdown like China and western countries, may not be affordable because of economic burden, hence improvising the imminent need for unprecedented health education programs to develop practices towards prevention to win this battle against COVID-19 pandemic. The overall poor knowledge and practice towards COVID-19 in this study suggests that health education interventions would be more effective if the health authorities organize the special education programs for prevention of COVID-19, which are specifically designed for certain ethnic groups of population, with low socioeconomic background, having low literacy rate, and especially targeting the elderly as well as housewives.

\section{ACKNOWLEDGEMENT}

The authors would like to thanks Dr. Humaira Mehmood, Dr. Zulfiqar Haider Naqvi, Dr. Mehmood and all the House Officers and Postgraduate trainee, for their practical contributions and all the participants involved in this study for their cooperation and support.

Copyright@ 28 Nov, 2020.

\section{REFERENCES}

1. Yang X, Yu Y, Xu J, Shu H, Liu H, Wu Y, Zhang L, Yu Z, Fang M, Yu T, Wang Y. Clinical course and outcomes of critically ill patients with SARS-CoV-2 pneumonia in Wuhan, China: A single-centered, retrospective, observational study. The Lancet Respiratory Medicine. 2020 Feb 24.
2. Mahase E. China coronavirus: WHO declares international emergency as death toll exceeds 200. Bmj. 2020 Jan 31; 368:m408.

3. Zhong BL, Luo W, Li HM, Zhang QQ, Liu XG, Li WT, $\mathrm{Li}$ Y. Knowledge, attitudes, and practices towards COVID-19 among Chinese residents during the rapid rise period of the COVID-19 outbreak: A quick online cross-sectional survey. International Journal of Biological Sciences. 2020; 16(10):1745.

4. Guest JL, del Rio C, Sanchez T. The three steps needed to end the COVID-19 pandemic: Bold public health leadership, rapid innovations, and courageous political will. JMIR Public health and surveillance. 2020; 6(2):e19043.

5. World Health Organization. Coronavirus disease (COVID-2019) situation reports.

6. Lai TH, Tang EW, Chau SK, Fung KS, Li KK. Stepping up infection control measures in ophthalmology during the novel coronavirus outbreak: An experience from Hong Kong. Graefe's Archive for Clinical and Experimental Ophthalmology. 2020 Mar 3:1-7.

7. Lu R, Zhao X, Li J, Niu P, Yang B, Wu H, Wang W, Song $H$, Huang B, Zhu N, Bi Y. Genomic characterisation and epidemiology of 2019 novel coronavirus: Implications for virus origins and receptor binding. The Lancet. 2020 Feb 22; 395(10224):565-74.

8. Gorbalenya AE. Severe acute respiratory syndromerelated coronavirus-The species and its viruses, a statement of the Coronavirus Study Group. BioRxiv. 2020 Jan 1.

9. Zhang L, Shen FM, Chen F, Lin Z. Origin and evolution of the 2019 novel coronavirus. Clinical Infectious Diseases. 2020 Feb 3.

10. Chan JF, Yuan S, Kok KH, To KK, Chu H, Yang J, Xing F, Liu J, Yip CC, Poon RW, Tsoi HW. A familial cluster of pneumonia associated with the 2019 novel coronavirus indicating person-to-person transmission: A study of a family cluster. The Lancet. 2020 Feb 15; 395(10223):514-23.

11. Lauer SA, Grantz KH, Bi Q, Jones FK, Zheng Q, Meredith HR, Azman AS, Reich NG, Lessler J. The incubation period of coronavirus disease 2019 (COVID-19) from publicly reported confirmed cases: Estimation and application. Annals of internal medicine. 2020 Mar 10.

12. Guan WJ, Ni ZY, Hu Y, Liang WH, Ou CQ, He JX, Liu L, Shan H, Lei CL, Hui DS, Du B. Clinical characteristics of coronavirus disease 2019 in China. New England Journal of Medicine. 2020 Feb 28. 
13. Chen L. Han. Yang F, Zhang tJ. 2001. [Epub ahead of print].

14. Gao WJ, Li LM. Advances on presymptomatic or asymptomatic carrier transmission of COVID-19. Zhonghua liu Xing Bing xue za zhi= Zhonghua Liuxingbingxue Zazhi. 2020 Mar 6; 41:485-8.

15. Chan KW, Wong VT, Tang SC. COVID-19: An update on the epidemiological, clinical, preventive and therapeutic evidence and guidelines of integrative Chinese-Western medicine for the management of 2019 novel coronavirus disease. The American journal of Chinese medicine. 2020 Mar 13:1-26.

16. Centers for disease control and prevention. Novel coronavirus, Wuhan. China. Information for Healthcare Professionals. https://www. cdc. gov/coronavirus/2019$\mathrm{nCoV} / \mathrm{hcp} / \mathrm{index}$. html (Accessed on February 14, 2020). 2019.

17. Chen ZL, Zhang Q, Lu Y, Guo ZM, Zhang X, Zhang WJ, Guo C, Liao CH, Li QL, Han XH, Lu JH. Distribution of the COVID-19 epidemic and correlation with population emigration from Wuhan, China. Chinese medical journal. 2020 Feb 28.

18. Guopeng $\mathrm{ZH}$, Chunhua $\mathrm{CH}$. A model simulation study on effects of intervention measures in Wuhan COVID-19 epidemic. Med Rxiv. 2020 Jan 1.

19. Zhang S, Wang Z, Chang R, Wang $H$, Xu C, Yu $X$, Tsamlag L, Dong $Y$, Wang $H$, Cai $Y$. COVID-19 containment: China provides important lessons for global response. Frontiers of Medicine. 2020 Mar 25:15.

20. WHO extends support to Pakistan as it confirms its first two cases of COVID-19. http://www.emro. who.int/pak/pakistan-news/who-extends-support-topakistan-as-it-confirms-its-first-two-cases-of-covid-19. $\mathrm{html}$ ? format $=\mathrm{html}$.

21. Confirmed COVID-19 cases reach 52 in Pakistan. https://nation.com.pk/15-Mar-2020/confirmed-covid-19cases-reach-52-in-pakistan.

22. https://www.who.int/emergencies/diseases/novelcoronavirus-2019/advice-for-public.

23. Taber KS. The use of Cronbach's alpha when developing and reporting research instruments in science education. Research in Science Education. 2018 Dec 1; 48(6):1273-96.

24. Person B, Sy F, Holton K, Govert B, Liang A. Fear and stigma: The epidemic within the SARS outbreak. Emerging Infectious Diseases. 2004 Feb; 10(2):358.
25. Zhong BL, Luo W, Li HM, Zhang QQ, Liu XG, Li WT, Li $Y$. Knowledge, attitudes, and practices towards COVID-19 among Chinese residents during the rapid rise period of the COVID-19 outbreak: A quick online cross-sectional survey. International Journal of Biological Sciences. 2020; 16(10):1745.

26. Zhong BL, Luo W, Li HM, Zhang QQ, Liu XG, Li WT, $\mathrm{Li} Y$. Knowledge, attitudes, and practices towards COVID-19 among Chinese residents during the rapid rise period of the COVID-19 outbreak: A quick online cross-sectional survey. International Journal of Biological Sciences. 2020; 16(10):1745.

27. ul Haq N, Hassali MA, Shafie AA, Saleem F, Farooqui $M$, Aljadhey $H$. A cross sectional assessment of knowledge, attitude and practice towards Hepatitis B among healthy population of Quetta, Pakistan. BMC Public Health. 2012 Dec 1; 12(1):692.

28. Mustafa RE, Mushtaq S, Akhtar N, Yameen MA. Assessment of knowledge, attitude and practice towards hepatitis among patients visiting the hepatitis clinic in tertiary care hospital, Rawalpindi, Pakistan. JPMA. The Journal of the Pakistan Medical Association. 2019 Aug; 69(8):1136-41.

29. Memon MS, Shaikh SA, Shaikh AR, Fahim MF, Mumtaz $\mathrm{SN}$, Ahmed N. An assessment of knowledge, attitude and practices (KAP) towards diabetes and diabetic retinopathy in a suburban town of Karachi. Pakistan journal of medical sciences. 2015 Jan; 31(1):183.

30. Bell E, Bryman A, Harley B. Business research methods. Oxford university press; 2018 Nov 5.

31. Saunders $M$, Lewis $P H$, Thornhill AD. Research methods. Business Students 4th edition Pearson Education Limited, England. 2007.

32. Selltiz C, Wrightsman LS, Cook SW, Golden G, Busha $\mathrm{CH}$, Harter SP. NOTES Chapter 4 Paul D. Leedy and Jeanne Ellis Ormrod, Practical Research: Planning and Design, (Boston: Pearson, 2016), 141. 2. Sage. 2013:11.

33. Memon J, Holakouie-Naieni $\mathrm{K}$, Majdzadeh R, Yekaninejad MS, Garmaroudi G, Raza O, Nematollahi $S$. Knowledge, attitude, and practice among mothers about newborn care in Sindh, Pakistan. BMC pregnancy and childbirth. 2019 Dec 1; 19(1):329.

34. Pakistan - statistics \& facts. https://www.statista.com/ topics/2666/pakistan/. 


\begin{tabular}{|c|l|l|l|}
\hline \multicolumn{3}{|c|}{ AUTHORSHIP AND CONTRIBUTION DECLARATION } \\
\hline Sr. \# & \multicolumn{1}{|c|}{ Author(s) Full Name } & \multicolumn{1}{|c|}{ Contribution to the paper } & Author(s) Signature \\
\hline 1 & Bushra Rabbani & $\begin{array}{l}\text { Main researcher and Main } \\
\text { author. } \\
\text { Research coordinator and } \\
\text { Questionnaire setting. } \\
\text { Author and Proof reading. }\end{array}$ \\
\hline 3 & Ammarah Saeed & Faisal Ahmed & $\begin{array}{l}\text { Data entry and Statistical } \\
\text { analysis. } \\
\text { Data collection. }\end{array}$ \\
\hline 5 & Hafiz Tahir Mehmood & Mata collection. \\
\hline 6 & Adil Khan & Dariam Tariq & \\
\hline
\end{tabular}

